\title{
Introduction, Outline and Acknowledgements
}

\author{
John P. Robinson
}

Accepted: 1 August 2008/Published online: 6 January 2009

(C) Springer Science+Business Media B.V. 2009

\section{Introduction, Outline and Acknowledgements}

Research on people's use of time is dramatically expanding its importance in informing both the social sciences and public policy making. More quantitative longitudinal diary research is being done in more countries by collecting and analyzing more national data, including a massive new US government time-diary survey that has attracted attention from a wide variety of academic disciplines. Enlightenment from these critical advances is amply illustrated in this issue.

Moreover, much new research is making it easier to interpret diary data in hours and minutes in quality-of-life (QOL) terms. Just in the first part of this issue, the reader will find:

(1) The promising steps being taken to translate diary time data into the meaning of these activities in terms of people's enjoyment or satisfaction.

(2) The emergence and detection of long-term historical trends in inequalities in free time, work, sleep and other daily activities by social class.

(3) The increasing interest and problems in translating time figures into economic benefits.

(4) The evidence and contributions of anthropologists and other "qualitative" researchers to document the increased "busyness" in the lives of the middle class.

The second part of this issue contains an additional 25 articles illustrating the significant scientific progress made on the vast variety of time-related topics that are being pursued by time-use researchers around the world, from child care to new media, from work schedules to life after retirement, or from husband-wife interactions to life in third-world countriesall to be described in more detail below.

J. P. Robinson $(\bowtie)$

Sociology Department, University of Maryland, College Park, MD, USA

e-mail: Robinson@socy.umd.edu 


\section{Background}

The 29th annual IATUR conference drew more than 200 researchers as presenters and discussants, about half from the US and half from nearly 30 other countries. Since this was the first IATUR conference held in the US, it offered a comprehensive platform for researchers from different countries and different disciplines to learn from and discuss each other's research.

This issue summarizes the highlights of this international time-use conference, one that has considerable relevance to social indicator research because of the recent availability of US national Census Bureau diary data in the American Time-Use Project ATUS) from more than 70,000 respondents since 2003-as well as the variety of American researchers addressing qualitative and other concerns about the quality of American daily life.

Many of the IATUR presenters compared their national results cross-nationally, particularly the initial plenary session, which identified 40-year trends in time-diary research, both in the United States and in comparison to other countries. The following session by Alan Krueger and his Princeton University team, has taken a leading role in adding affect data to time-diary accounts. Its eventual goal is the application of these methods to the ATUS to enrich measures of national well-being (as simulated in Fig. 2 of their article on 1965-2005 changes). This session aroused considerable attention among conference participants, since it pointed out unresolved issues and prior research that had been done on these topics, as raised in a follow-up discussion session covered next in this issue.

\subsection{Plenary Topics}

\subsubsection{National Time Accounts (NTA)}

The lead article in this volume describes the impressive progress made by this Princeton University research team in incorporating measures of affect into various uses of time. These measures are then applied to comparative analyses of the daily QOL in (1) the US versus France in 2006 (in which the French seem to have some advantage), and (2) the US in 1965 versus the US in 2005, in which it appears that women have lost slightly in their QOL since 1965, while men have stayed about the same. A main factor here is the much less positive rating of paid work using the authors' U-index-and work of course has become much more prominent in the lives of women since 1965. The hope here is that these early steps toward "National Time Accounts" can augment the current economic measures of the overall health of the country, like the gross domestic product (GDP).

\subsubsection{Time-Use Trends, 1960-2005}

The next set of articles examines some general social trends in time use over the last 40+ years that is since the first diary surveys conducted in the 1960s. In both the US and most other Western countries, free time has increased (presumably thought to be a big plus in QOL terms), although there is some question about whether the activity at the forefront of that increase-TV - can be viewed so positively. The main activity allowing that increase in free time for women is (decreased) housework, and usually seen as a part of a more positive and welcome trend of gender convergence (or androgeny) in the daily lives of men and women. 
More on the down side, however, is that the free-time increase is unequally distributed, possibly because of underemployment among the less educated compared with the college educated, again both in the US and other Western countries. That suggests that Thorsten Veblen's famed portrayal of a "leisure class" $100+$ years ago has been turned on its head-from there being a money-rich time-rich upper class to their becoming a money-rich time-poor class.

\subsubsection{Economists and Time}

The increased attention of economists to time-use issues and measures is another positive step, given their advanced tools for quantitative modeling and their greater experience in crucial theorizing. There is a call, however, for economists to make greater use of these tools and theories in their time-use research, rather than simply repeating the standard modeling of other social scientists-with paid work being a central area of interest. Also noted in this set of articles by three distinguished economists are (1) the increasing use of event history calendars (EHCs) to embellish the simple data on average time spent on various activities, as well as (2) the limitations of conventional economic thinking in documenting living standards and determining when one is really "better off".

\subsubsection{Qualitative Sloan Studies}

The final set of articles based on plenary session presentations involves parallel contributions and advances from the field of anthropology, giving us another rich body of qualitative evidence to use in interpreting time-diary data. This qualitative research on daily life has been stimulated by several grants funded by the Alfred P. Sloan Foundation's program on the Workplace, Workforce and Working Families, and generally has the advantages of direct observation and of usually employing panel studies of the same families across time. Using "scan sampling" applied to videotapes, these Sloan studies do document directly the complex busyness of today's middle-class parents that may be missed in diary studies.

Their extensive mapping of family spaces in everyday family life also identify how central the kitchen (and particularly kitchen tables) is as a "command center" for family living - which is ironic given how little attention and space kitchens were given by home builders. Other anthropologists funded by Sloan are obtaining verbal accounts of how family members create family memories centered around routine rituals and important life events or epochs. In this session as well is a review of two important methodological studies from the Sloan program, one comparing the UCLA video samples with the ESM "beeper" data, and the other comparing the ESM approach with time diaries. These highlight some major strengths and weaknesses of all three approaches.

\subsection{Targeted Topics}

As noted above, the second part of this issue highlights the main conclusions from the 25 more specifically targeted IATUR topics, most of which also have QOL implicationssuch as whether children spend their time "productively" in doing school homework, whether and what type of parenting time most predicts benefits to children, aspects of the extent and quality of work schedules, whether married people are spending more free time together, and time use among selected social groups (women, working-class differences, senior citizens, rural residents, cell phone users and workers with long hours). Finally, 
novel results were presented on new methods of collecting and analyzing time data, especially those employing multiple methods on a comparative basis.

These articles are grouped into five general topic areas:

(1) Children's time;

(2) Parent-spouse relation;

(3) Paid work hours;

(4) Leisure and technology;

(5) Methods.

\subsubsection{Children}

The section on children begins with Jiri Zuzanek's multi-method, international analysis of homework time, in which he concludes that, rather than being a prime source of children's stress and unhappiness, homework time (a) amounts to only about 7-10 h a week across nine countries, (b) has not increased across time, and (c) may be more stressful, unhappy and boring than other free-time activities-but less so than certain other activities-most notably time spent in the classroom. Also on the topic of homework, Charlene Kalenkoski and Sabrina Pabilonia's analysis of recent ATUS data on 15-19 year-olds concludes that every hour on a job means that teens will spend about 15 min less time doing homework during the week, but less than 5 min less on weekends.

Using children's data from the PSID panel study, Amy Hsin concludes that both a mother's verbal skill and her time in more "developmental" activities are associated with greater verbal skills for her children. Using that same PSID data base, Sandra Hofferth finds some important shifts in children's time use between 1999 and 2006, with the increasing use of videogames and other new technologies posing some new challenges in child development. Also troubling in terms of American children's use of time is Eva Osterbecka and Cathleen Zick's finding that their engagement in more enriching activities (reading, writing, family meals and the like) in the ATUS is significantly lower than reported in time diaries reported by Finnish adolescents.

\subsubsection{Parent-Spouse Relations}

Also comparing ATUS data with comparable Scandinavian data, Hirimi Ono and Rosemary Yeilding find that cohabiting fathers in the US spend less time in child care than married fathers, but no less time than in Sweden, perhaps reflecting the equal treatment afforded cohabiting fathers in that country. Rong Wang and Suzanne Bianchi's analysis of fathers in the ATUS finds that fathers with working wives do spend more time on child care than if the mother does not work, especially if they have preschool children.

Rachel Connelly and Jean Kimmel's analysis of ATUS parents finds little evidence that husbands' or wives' work hours or wages have much effect on their spouse's activity patterns. On the other hand, Sanjiv Gupta, Liana Sayer and Philip Cohen find that ATUS women with higher incomes and education do spend more of their own time on healthrelated activities, non-traditional housework and child care-and less time on traditional (core) housework and other leisure activities.

In South Africa, Martin Wittenberg finds that his new household "connectedness" measure is quite predictive of more beneficial activities being chosen. Comparing married people in the ATUS with those in previous US diary studies, Marieke Voorpostel, Tanja van der Lippe and Jonathan Gershuny find that they are spending more of their free time 
with each other, consistent with the Anthony Giddens notion of a "transformation of intimacy".

\subsubsection{Paid Work}

The first three articles in this section examine the little-researched area of work schedules. Laurent Lesnard takes advantage of a new "work grid" measure (in which French respondents report their time at work at 15-min intervals across the entire week) to derive four basic types of schedules (standard, long, fragmented and short). Only $36 \%$ of French workers fit the stereotypical 9-5 schedule-with parallel results being found in Australia. Using the more usual daily diaries instead, Ignace Glorieux and his colleagues estimate that $63 \%$ of Belgian workers work a standard schedule (up from 56\% in 1966), but that the proportions working across the day is down dramatically-quite contrary to the popular model of a " $24 / 7$ economy". Using a more qualitative and multi-method approach, combining depth interviews, observations and organizational documents, in addition to surveys, Dan Clawson, Naomi Gerstel and Jill Crocker describe four widely-different types of US work-family life-styles that vary by whether the family's versus the employer's work hours are flexible or rigid.

Harley Frazis and Jay Stewart employ a variety of measurement adjustments in the ATUS data to show the basic convergence of these diary work-hour data with the work estimates of respondents in the current population survey (CPS). Also based on the ATUS data, Vanessa Wight and Sarah Raley find little evidence that working at home makes one's life go no smoother than work at the office or factory, and that few home-based workers cite work-family balance as the reason for their working at home. Hannu Paakkonen contrasts paid and unpaid work hours across four European countries with different work "regimes", and he finds that total workloads of men and women in Finland, Germany and the UK are basically equal, while in Spain women work longer hoursbecause more domestic work needs to done.

As something of a bridge between the work section and the next section on leisure, David Cotter and Younghwan Song use ATUS data to find conflicting evidence about whether long work hours are associated with both more and less religious attendance.

\subsubsection{Leisure, Space and Technology}

Liana Sayer and Janet Gornick begin this section by examining ATUS and diary data from seven other Western countries on the life styles of older adults to find that employment status has more impact than age per se and that being employed is associated with "healthier" patterns of leisure in later life.

Arnaldo Mont' Alvao and Neuma Aguiar examine travel patterns in diary data from a large Brazilian city to find that not only are higher status people able to travel more during a day, but that they can do so more efficiently by having an automobile than using mass transit (and taking up more travel space as well). H. K. Cho and colleagues find that poorer farm families in Korea are especially disadvantaged during slack periods rather than in the growing season.

Turning to new IT, Michael Bittman, Jude Brown and Judy Wajcman allay fears that the "always on" feature of cell phones makes their Australian users feel more time pressured or imposed upon by work demands during free time; but usage does appear to intensify work time. Nakano Sachiko and Yoko Watanabe report a virtual doubling of Internet use 
and time in Japanese media diaries between 2001 and 2006 in all age groups, but especially among people under age 30 .

\subsubsection{Methods}

A number of presentations at IATUR 2007 were concerned with methodological advances, such as the EHC analyses described above by Frank Stafford and the qualitative time analyses covered in the Sloan Foundation session. Among the other methods presentations, two in particular stood out as innovative. First, using two UK diary studies one of which also collected time-estimate data, Man Yee Kan and Jonathan Gershuny describe techniques for using the time-diary data to calibrate and derive more plausible time-use estimates, so that the two produce figures that are generally within $15 \%$ of each other, and sometimes within 5\%. Second, Michael Holmes and Mike Bloxham describe an observational diary based on direct observation by a reporter "shadowing" the respondent, a diary that captures far higher media usage than reported in typical time diaries.

Also in this final methods section, Kimberly Fisher has arrayed the latest (mainly national) diary data from more than 12 countries, both for comparison across these countries and across time.

Acknowledgements The richness of our 2007 IATUR conference would not have been possible without the support provided by several key individuals and organizations. The Maryland Population Research Center (MPRC), the Department of Sociology and the College of Behavioral Sciences (BSOS) at the University of Maryland provided generous organizational, administrative and financial support for the conference. The participation of scholars from third-world countries was made possible by a grant from the Economic Research Service (ERS) of the US Department of Agriculture, and the Alfred P. Sloan Foundation underwrote the opening reception at the conference. In particular, Katherine Abraham and Suzanne Bianchi provided the leading roles in organizing the overall program (that changed often due to author schedules and space availability), of successful implementation of staff and material support and of obtaining outside funding. Karen Hamrick, Jay Stewart, Sandra Hofferth and Kathleen Christiansen organized and made possible the session series on food, work, family and qualitative studies, respectively. Zsuzsa Daczo and Barbara Hillinger were responsible for carrying out the details of this planning. In addition, grateful recognition is due to the staff at the Bureau of Labor Statistics, not only for sharing and providing their facilities but for organizing the hospitality that made the conference such a memorable experience. We also are grateful to the following individuals who acted as members of our editorial board in reviewing and critiquing the various articles in this issue: Sandra Hofferth (University of Maryland); Liana Sayer (Ohio State University); Jay Stewart (US Bureau of Labor Statistics); Michael Bittman (University of New England, Australia); Jonathan Gershuny (Oxford); Kimberly Fisher (Oxford); Frank Stafford (University of Michigan); William Michelson (University of Toronto); Jiri Zuzanek (University of Waterloo); Laurent Lesnard (Sciences: PO); Ignace Glorieux and colleagues (University of Brussels); Finally, Andrew Caporaso took responsibility for maintaining continual contact with the various authors and editing their texts and tables into uniform formats, with assistance from Samuel Kart. 